\title{
Laboreal
}

Volume $12 \mathrm{~N}^{\circ} 1 \mid 2016$

Os Equipamentos de Proteção Individual (EPI):

protetores, mas nem sempre

\section{La influencia de la percepción del riesgo en la utilización de los equipos de protección individual contra los pesticidas}

A influência da perceção de risco sobre o uso dos equipamentos de proteção individual contra os pesticidas

L'influence de la perception du risque sur l'usage des équipements de protection individuelle contre les pesticides

The influence of risk perception on the use of personal protective equipment against pesticides

\section{Carolina Ullilen-Marcilla y Alain Garrigou}

\section{(2) OpenEdition}

\section{Journals}

Edición electrónica

URL: http://journals.openedition.org/laboreal/2850

DOI: 10.4000/laboreal.2850

ISSN: 1646-5237

Editor

Universidade do Porto

\section{Referencia electrónica}

Carolina Ullilen-Marcilla y Alain Garrigou, « La influencia de la percepción del riesgo en la utilización de los equipos de protección individual contra los pesticidas », Laboreal [En línea], Volume 12 №1 | 2016, Publicado el 01 julio 2016, consultado el 07 octubre 2019. URL : http://journals.openedition.org/ laboreal/2850 ; DOI : 10.4000/laboreal.2850

Este documento fue generado automáticamente el 7 octubre 2019.

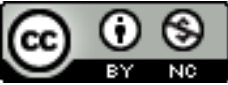

Laboreal está licenciado com uma Licença Creative Commons - Atribuição-NãoComercial 4.0 Internacional. 


\section{La influencia de la percepción del riesgo en la utilización de los equipos de protección individual contra los pesticidas}

A influência da perceção de risco sobre o uso dos equipamentos de proteção individual contra os pesticidas

L'influence de la perception du risque sur l'usage des équipements de protection individuelle contre les pesticides

The influence of risk perception on the use of personal protective equipment against pesticides

\section{Carolina Ullilen-Marcilla y Alain Garrigou}

\section{NOTA DEL EDITOR}

http://dx.doi.org/10.15667/laborealxii0116cum

Manuscrito recebido em: março/2016

Aceite após peritagem: junho/2016

Un especial agradecimiento a los cinco viticultores que participaron en este estudio.

\section{Introducción [1]}

1 Los pesticidas son sustancias que permiten erradicar o limitar la propagación de enfermedades en las plantas cumpliendo con el objetivo de proteger los cultivos, generalizándose su uso con el tiempo por sus resultados, bajos precios y fácil aplicación (Gatignol \& Etienne, 2010). Cabe señalar que Francia es el primer consumidor de 
pesticidas en Europa y cuarto a nivel mundial por detrás de Estados Unidos, Brasil y Japón (UIPP et al. citado por Ministère de l'environnement, de l'énergie et de la mer, Francia). El cultivo de la vid representa el $20 \%$ del consumo nacional de pesticidas en Francia (Aubertot et al., 2005).

2 Ahora bien, la utilización de los pesticidas en el sector agrícola representa un riesgo importante para la salud. De hecho, el grupo que está más expuesto son los trabajadores que realizan la preparación, transporte y aplicación de estos productos en los campos agrícolas. Por las características de su actividad, tienen una mayor exposición a riesgos con elevados índices de intoxicación (Fenske \& Day, 2005).

3 Ante los cuestionamientos sobre los efectos negativos de los pesticidas en la salud, el estudio de Baldi et al. $(2001 ; 2011)$ muestra la disminución de las capacidades neurocomportamentales en los viticultores. El trabajo de Multigner (2005) señala el desarrollo de ciertos canceres poco frecuentes pero con una incidencia más elevada en el trabajador agrícola, por ejemplo, cáncer del cerebro, del sistema hematopoyético (leucemia, mieloma, linfoma), del estómago, de la próstata, entre otros.

4 No obstante, se han llevado a cabo una serie de esfuerzos para reducir la exposición profesional a los pesticidas, los cuales han sido insuficientes. Garrigou, Baldi y Jackson (2012) señalan las limitaciones de los equipos de protección individual (ej. los problemas de permeación del traje tipo 4 por ser parcialmente eficaces, pudiendo migrar el pesticida al interior), el diseño de las maquinarias agrícolas que se centra principalmente en riesgos mecánicos y no se toma en cuenta las diferentes situaciones de contaminación en la fase del diseño (ej. cabina del tractor); los modelos toxicológicos utilizados en el mercado no corresponden al contexto social, técnico y cultural, incluido los programas de capacitación.

5 El estudio Pestexto, dirigido por Baldi et al. (2006) en el departamento galo de Gironda, ha permitido medir la contaminación real en los viticultores por contacto cutáneo de las manos y del aparato respiratorio en cada fase de la actividad laboral, mostrando que el equipo de protección individual no evita la contaminación. Los resultados muestran que el uso del traje de seguridad en la etapa de preparación, solo limita parcialmente la contaminación, señalando que durante las etapas de aplicación y limpieza de los materiales agrícolas, las personas que utilizan el traje, resultan más contaminadas que aquellas personas que no lo utilizan.

6 Además, de las 67 observaciones de los tratamientos agrícolas, se encontró que el 50\% de los viticultores no utilizaban guantes, el $58 \%$ no utilizaban trajes, el $61 \%$ no utilizaban máscara (Garrigou, Baldi \& Dubuc, 2008).

7 Si bien los dispositivos técnicos (ej. equipos de protección, maquinaria agrícola) presentan ciertas deficiencias en su diseño, es importante señalar que la no utilización o utilización incorrecta de los equipos de protección individual (EPI) puede conllevar a acciones peligrosas. Esto se explicaría por el hecho de que los comportamientos de los trabajadores estarían determinados no sólo por las restricciones que pesan en su actividad, sino también por sus creencias, sus representaciones de los riesgos y de lo que ellos sienten.

8 En efecto, se nos presenta una realidad ya que los viticultores tienen cierto nivel de consciencia de que su actividad puede producir daños a su salud, sin embargo, en la práctica, se protegen poco. Nuestro desafío busca responder a la interrogante acerca de la influencia de la percepción del riesgo en modificar comportamientos humanos. 
9 Dada la escasez de investigaciones sobre el tema, hemos considerado pertinente contribuir, a pesar de las limitaciones del estudio, a la formalización de esta problemática.

10 Este trabajo comprende seis secciones. En la segunda sección, se aborda el marco teórico, en la tercera sección, se plantea la hipótesis, en la cuarta sección, se presenta a la población objeto de estudio y la metodología, en la quinta sección, se presentan los resultados del estudio y en la sexta sección, se señalan las conclusiones y discusiones.

\section{Marco teórico}

Resulta necesario señalar la diferencia de dos conceptos: la representación y la percepción de los riesgos. En cuanto a la primera, la representación resulta de un tratamiento cognitivo de la realidad (Perreti-Watel, 2000, citado por Chevreau, 2009) y la percepción constituye las sensaciones que el individuo siente frente a una situación (Chevreau, 2009). El concepto de la representación parece más compleja, ya que la persona recurre a diferentes procesos intelectuales y su racionalidad es limitada en el tratamiento de toda la información.

En lo que concierne a la percepción del riesgo, este concepto juega un rol importante en la decisión de protegerse o no frente al peligro. Estudios en psicología sobre la adopción de comportamientos seguros o peligrosos concluyen que las actitudes y las creencias son factores determinantes en la adopción de un comportamiento, dónde una percepción adecuada de los riesgos puede conducir a la adopción de comportamientos seguros (Kouabenan, 2006a).

13 Kouabenan y Cadet (2005, citado por Kouabenan 2006b) señalan que la percepción del riesgo es un proceso complejo, estructurado por diferentes variables relacionadas a las características del individuo y a la naturaleza del riesgo. Pues, la evaluación subjetiva del riesgo depende de múltiples variables: variables individuales o psicológicas (edad, sexo, creencias...), variables cognitivas (expertise, tratamiento de la información...) variables sociales, políticas, religiosas, etc.

14 Kouabenan (2008) señala que cada persona confrontada a diferentes situaciones de trabajo tiene representación propia de los riesgos, una idea de las consecuencias de los accidentes pero también la manera de prevenirlos. En efecto, sus representaciones y creencias impactarán en su percepción y esta percepción puede influir en sus comportamientos. De este hecho, las reacciones de las personas no son las mismas frente al peligro. Algunas asumirán más riesgos que otras.

Además, Kouabenan (2006b) advierte que las creencias pueden conllevar a "sesgos o ilusiones" en la percepción del riesgo, entre las más citadas en la literatura:

- Superioridad o sobre confianza: tendencia a creerse más apto en comparación a los demás para enfrentar los riesgos

- Optimismo irrealista o ilusión de control: creer que los eventos positivos son más probables que los eventos negativos.

- Ilusión de invulnerabilidad: percibirse poco susceptible de sufrir las consecuencias de un evento negativo.

Por otro lado, el riesgo puede construirse en el seno de un colectivo. El estudio de Duclos (1987) en el sector químico muestra que los obreros tienen ciertos conocimientos de los riesgos. En las entrevistas, el autor constata diferentes 
argumentos, entre los cuales: la negación del riesgo, la minimización del riesgo, el énfasis del riesgo, la dramatización del riesgo, la relativización del sinceramiento de los demás, los discursos contradictorios sobre el riesgo.

El estudio pone en evidencia que el contexto puede crear un sentimiento colectivo del riesgo, donde la prevención es "simbólica", la cual busca más proteger las relaciones sociales que reducir el riesgo, conllevando a que un accidente no necesariamente catastrófico puede ser un factor de desequilibrio de las relaciones laborales.

\section{Hipótesis}

La percepción del riesgo puede influenciar en el comportamiento de los operadores cuando están expuestos a peligros. En consecuencia, nos planteamos la siguiente interrogante: ¿ciertos factores internos relacionados con las características propias de los viticultores podrían influenciar en sus comportamientos?

\section{Población y metodología}

\subsection{Población}

La intervención ergonómica se realizó en tres viñedos pertenecientes al departamento francés de Aquitania. Cada viñedo tiene entre 30 y 40 hectáreas (H) y 1 ó 3 trabajadores de todo el personal. No fue sencillo contar con la participación de más viñedos, a pesar de tener una lista y contactar directamente a los responsables. Tuvimos que buscar intermediarios con el fin de interceder.

Precisamos que en veinte años, el número de trabajadores permanentes se redujo a la mitad en las explotaciones agrícolas en Francia, tres cuartas partes de estos empleados trabajan en explotaciones medianas y grandes (INSEE, Francia).

Tabla1: Características de los viñedos²

\begin{tabular}{|c|c|c|c|}
\hline Viñedo & Tamaño & Tipo de viticultura ${ }^{[2]}$ & $\mathrm{N}^{\circ}$ de viticultores \\
\hline Viñedo 1 & $30 \mathrm{H}$ & $\begin{array}{l}2 \mathrm{H} \text { viticultura biológica } \\
28 \mathrm{H} \text { viticultura convencional }\end{array}$ & $\begin{array}{c}1 \\
\text { (V1) }\end{array}$ \\
\hline Viñedo 2 & $39 \mathrm{H}$ & Viticultura convencional & $\frac{3}{(\mathrm{~V} 2, \mathrm{~V} 3 \text { et } \mathrm{V} 4)}$ \\
\hline Viñedo 3 & $30 \mathrm{H}$ & Viticultura razonada & $\begin{array}{c}1 \\
\text { (V5) }\end{array}$ \\
\hline
\end{tabular}


En lo que concierne al material agrícola, los tres viñedos cuentan con uno o dos tractores con cabina climatizada y un tanque en cada lado. En el viñedo 1, la mezcla se realiza en un reservorio, en el viñedo 2 , en una cisterna, en el viñedo 3 , en un incorporador.

Figura 1: Tractor

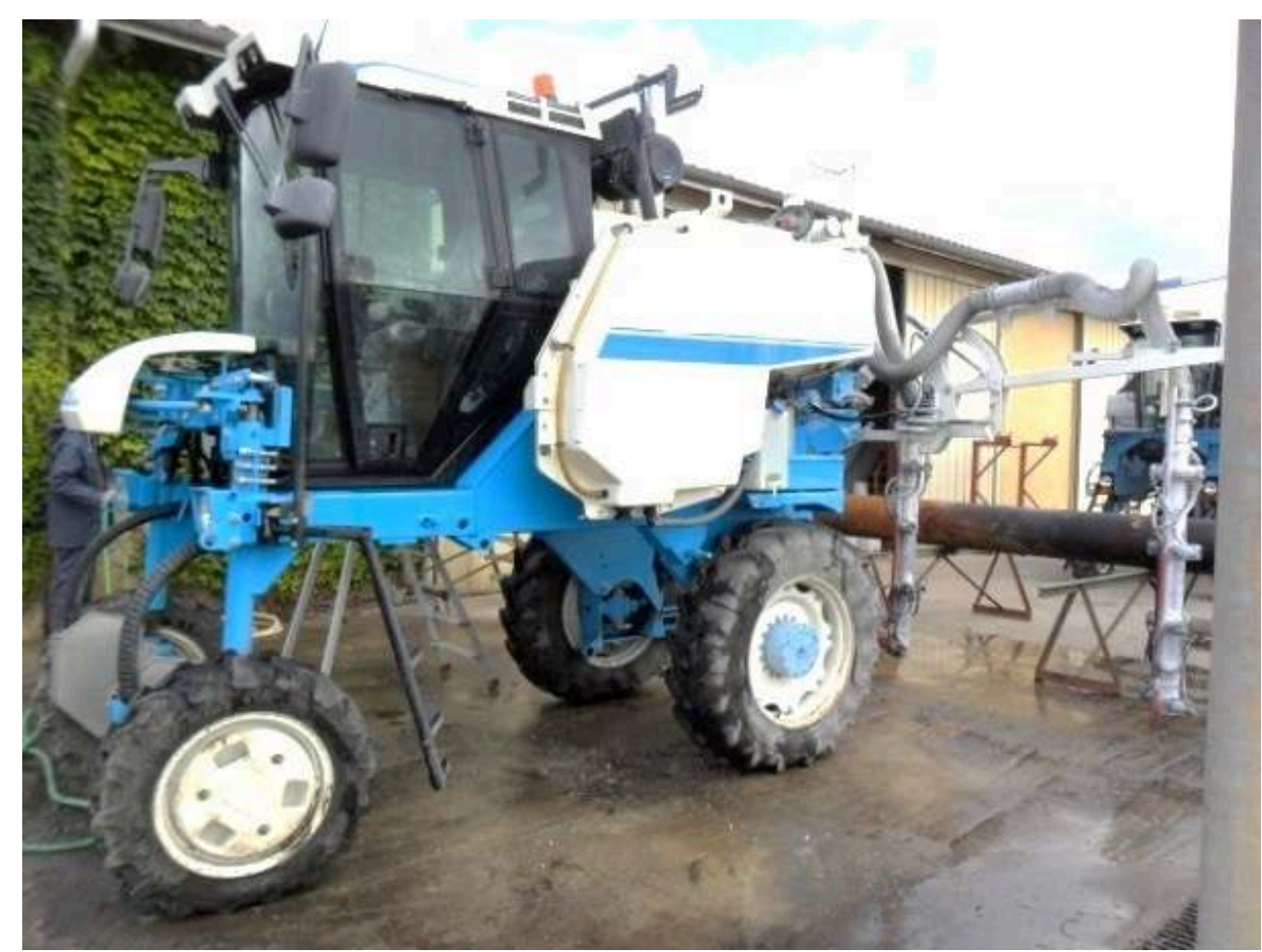

\subsection{Metodología}

La metodología de este estudio se basa en el "análisis de la actividad", buscando comprender las estrategias que adoptan los operadores en el desarrollo de su trabajo. Es importante tener presente que la actividad se compone de dos partes, una parte observable que constituye los comportamientos pudiendo ser registrado a través de diferentes soportes técnicos, y otra parte inobservable que es interno a la persona y accesible gracias a las diferentes técnicas de entrevistas (Cahour, 2006).

Aquí, el comportamiento de la persona se convierte en objeto de estudio, cuestionando en todo momento sus vivencias con el objetivo de comprender sus dificultades para protegerse de los pesticidas.

\section{Elección de las situaciones a estudiar}

Los pesticidas en este sector agrícola son utilizados para el tratamiento de los viñedos protegiendo los cultivos contra los organismos dañinos. El tratamiento comprende tres etapas:

- Antes del tratamiento: preparación de la mezcla

- Durante el tratamiento: aplicación de la mezcla en los cultivos.

- Después del tratamiento: limpieza de los materiales agrícolas. 
El uso de los EPI (traje impermeable de seguridad para evitar el ingreso de partículas al cuerpo, un par de botas, guantes de nitrilo, mascara con cartucho filtrante gas y partículas, lentes de seguridad en caso de salpicaduras) es obligatorio en la primera y última fase. Durante el tratamiento, la cabina debe estar presurizada, el trabajador se retira sus EPI para evitar contaminar su cabina, es recomendable tener guantes en el tractor para las intervenciones y evitar entrar en contacto con la nube vaporizada.

\section{Recojo de información}

Para comprender las actividades de los viticultores, se llevaron a cabo una serie de observaciones directas en cada viñedo, unas durante la preparación de la mezcla y otras durante la limpieza de los materiales agrícolas, siendo filmadas in situ.

En el caso de la aplicación de la mezcla, está prohibido ingresar a los cultivos para evitar la exposición a los pesticidas, siendo colocada una cámara en la frente del viticultor. Algunas visitas fueron suspendidas debido a la presencia de fuertes lluvias.

La tabla 2 indica el número de visitas para realizar las observaciones en cada viñedo, durante el período de intervención. Habíamos coordinado más visitas pero fueron suspendidas por las condiciones climáticas.

Tabla 2: Número de visitas para las observaciones

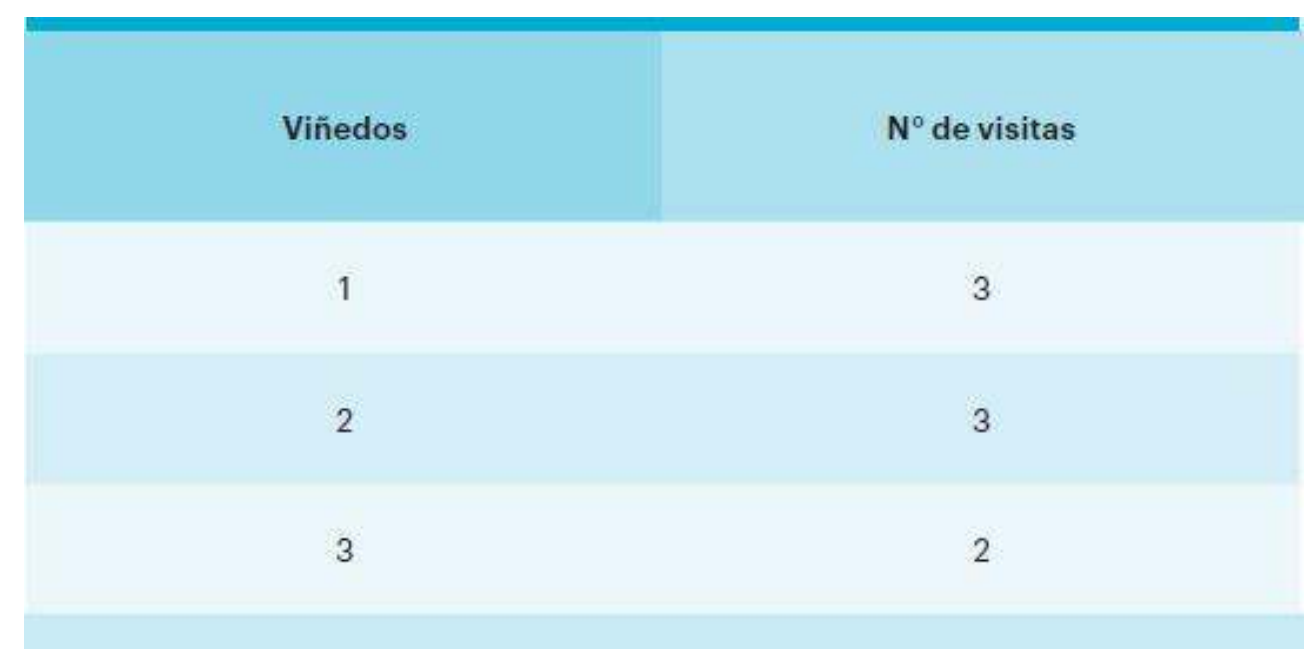

31 La tabla 2 indica el número de visitas para realizar las observaciones en cada viñedo, durante el período de intervención. Habíamos coordinado más visitas pero fueron suspendidas por las condiciones climáticas.

El tiempo de observación es variable. En la preparación de la mezcla (1), la duración depende de la cantidad de pesticidas que se mezclará, la cantidad de envases a enjuagar, la presencia de fallas repentinas en los equipos, el número de viticultores. En la aplicación de la mezcla en los campos (2), la duración depende de la cantidad programada de hectáreas, pudiendo extenderse si las condiciones climáticas no son favorables y si hay averías o fallas repentinas en los equipos. Principalmente, se observó por más tiempo al viñedo 1 debido a las frecuentes paradas. En la limpieza de materiales (3), la duración varía en función del diseño del tractor, algunos necesitan un enjuague rápido y otros requieren ser limpiados pieza por pieza. 
Tabla 3: Duración aproximada de observación por etapa

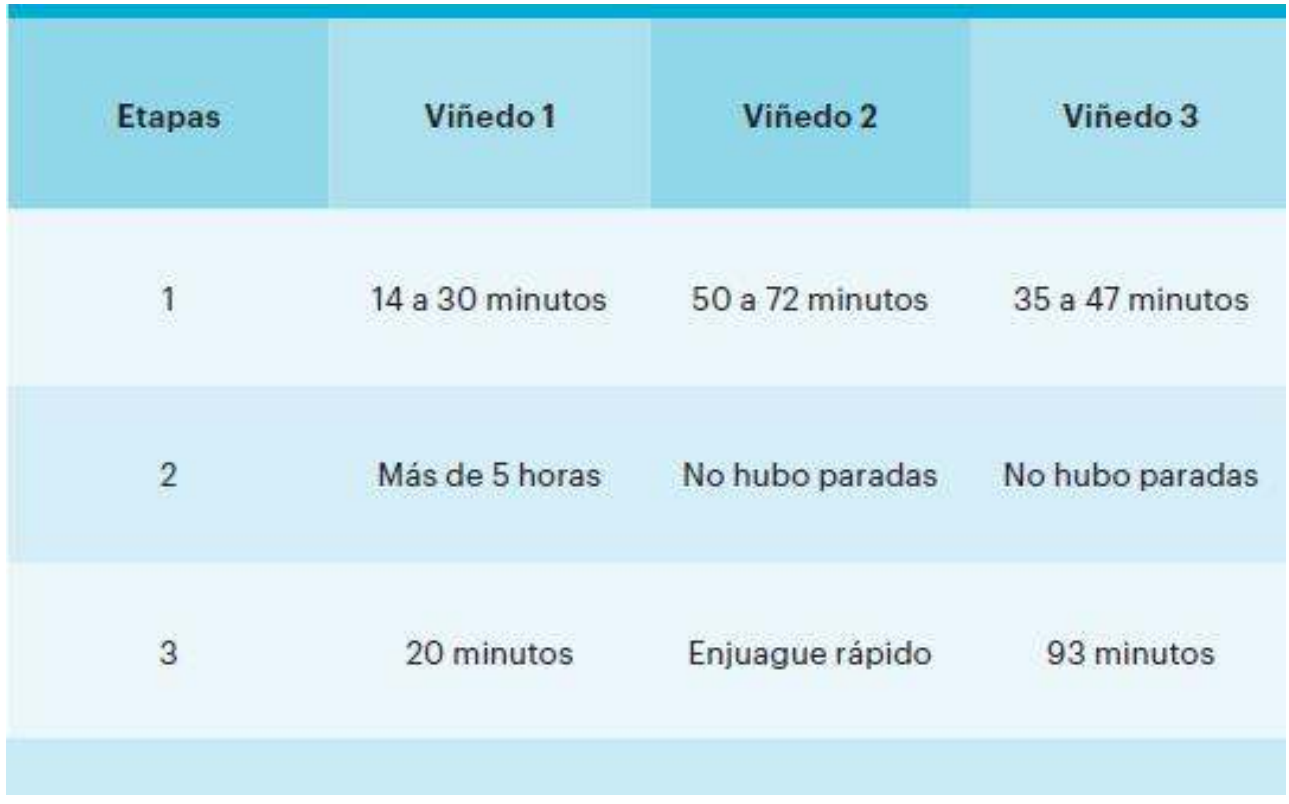

La tabla 4 señala los EPI utilizados para la preparación de la mezcla y limpieza de materiales.

Tabla 4: EPI utilizados por los viticultores

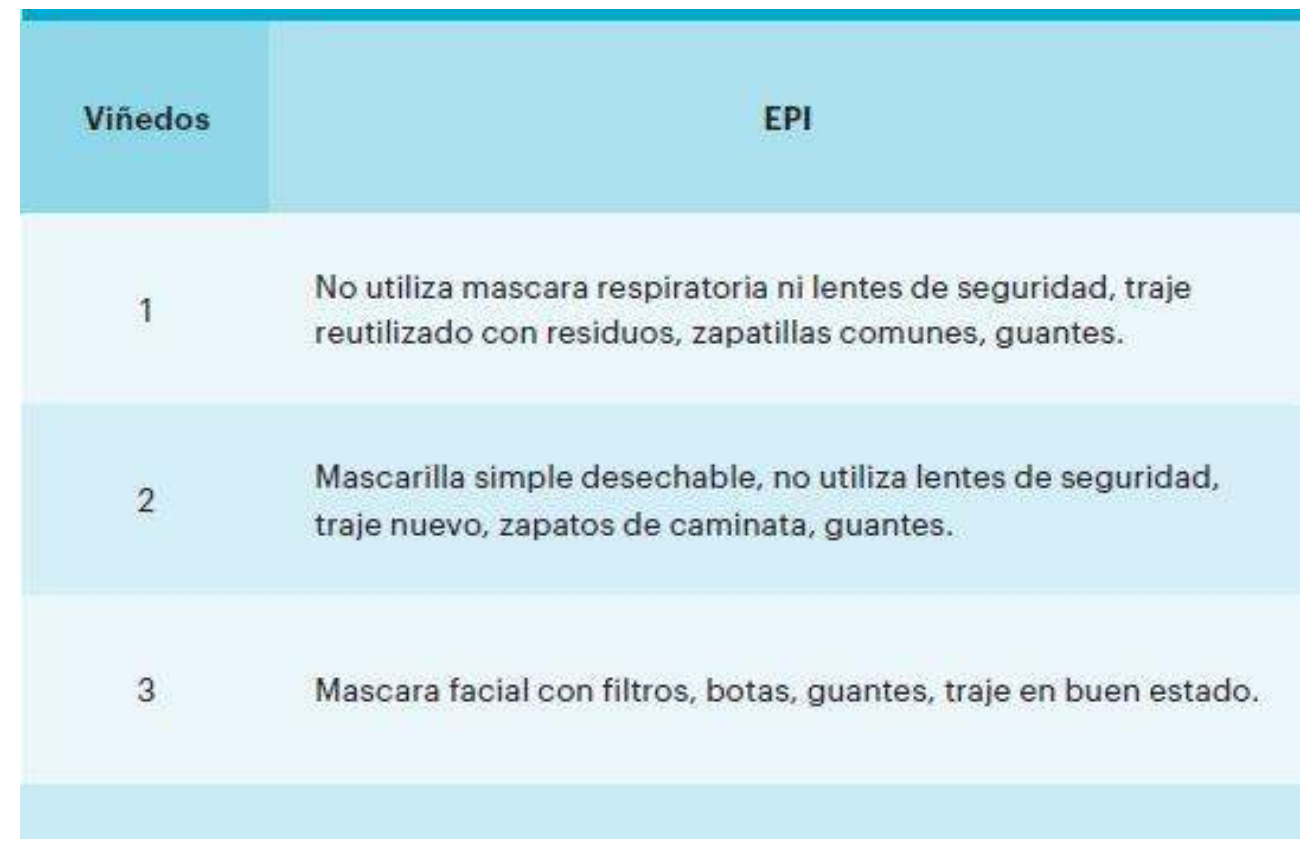

Los objetivos del estudio fueron presentados a cada responsable del viñedo. A los viticultores se les explico el motivo de nuestra presencia, la cual estaría relacionada en analizar las dificultades que tienen en el desarrollo de sus actividades, evitando alterar sus comportamientos rutinarios.

Para el recojo de información, se elaboró una ficha de observación en base a las guías de las buenas prácticas agrícolas, en la cual se incluyen datos sobre la manipulación 
correcta de los pesticidas, la buena utilización de los materiales agrícolas, el uso de los EPI y el buen mantenimiento de todos los materiales y equipos utilizados.

No fue posible realizar preguntas de manera simultánea cuando los trabajadores estaban utilizando sus máscaras de protección. Para estos casos, se realizaron entrevistas después de sus tareas observadas previamente, para informarnos de sus actividades, valoraciones y creencias laborales.

También se desarrolló Fichas de entrevista para ser empleada en cada etapa de los tratamientos agrícolas. Para la elaboración de éstas se tomaron como base los estudios en ergotoxicología y la encuesta "Perceptions des risques sanitaires encourus par les utilisateurs de pesticides" por Baert et al. (2003). La mayoría de los diálogos fueron grabados para posteriormente ser analizados y codificados.

38 Cabe precisar que siendo el tiempo de los viticultores limitado para las entrevistas, en el caso del viñedo 1 y 2, optamos por acompañarlos en su jornada después de los tratamientos agrícolas para obtener mayor información.

39 Además, se realizaron entrevistas de auto-confrontación en base a las observaciones realizadas. Esta técnica permitió confrontar al viticultor con lo que él realizó laboralmente. Para ello, se seleccionaron ciertas secuencias de los videos y cada entrevista tuvo una duración aproximada de 30 minutos debido a su disponibilidad de tiempo.

\section{Resultados}

40 A continuación se presentan los resultados del trabajo prestando una especial atención en analizar los factores internos relacionados a las características del trabajador que podrían influenciar en su percepción del riesgo.

\subsection{Formación}

La formación o capacitación en la utilización y el mantenimiento de los EPI contribuyen en reducir la exposición a los pesticidas, siendo insuficiente en caso, no se transmita bien la información y no se proporcionen los equipos de protección y materiales adecuados.

42 En el caso del V1, el cual no ha recibido formación alguna, manifiesta: "lo hacemos de manera natural", además que el vendedor no le ha explicado cómo utilizar sus equipos, " sólo nos entrega el producto, es todo, estamos en el mundo del dinero, después no les interesa". Señala que los EPI como el traje es para no ensuciarse y la máscara es utilizada en función de la supuesta toxicidad del pesticida.

43 A parte de no haber recibido formación, tampoco cuenta con los equipos de protección necesarios en forma permanente, como por ejemplo, la máscara. Por otro lado, calza sus zapatillas en lugar de botas y tiene el traje pero no lo utiliza de manera cotidiana. 
Figura 2: Vertimiento de pesticidas al reservorio

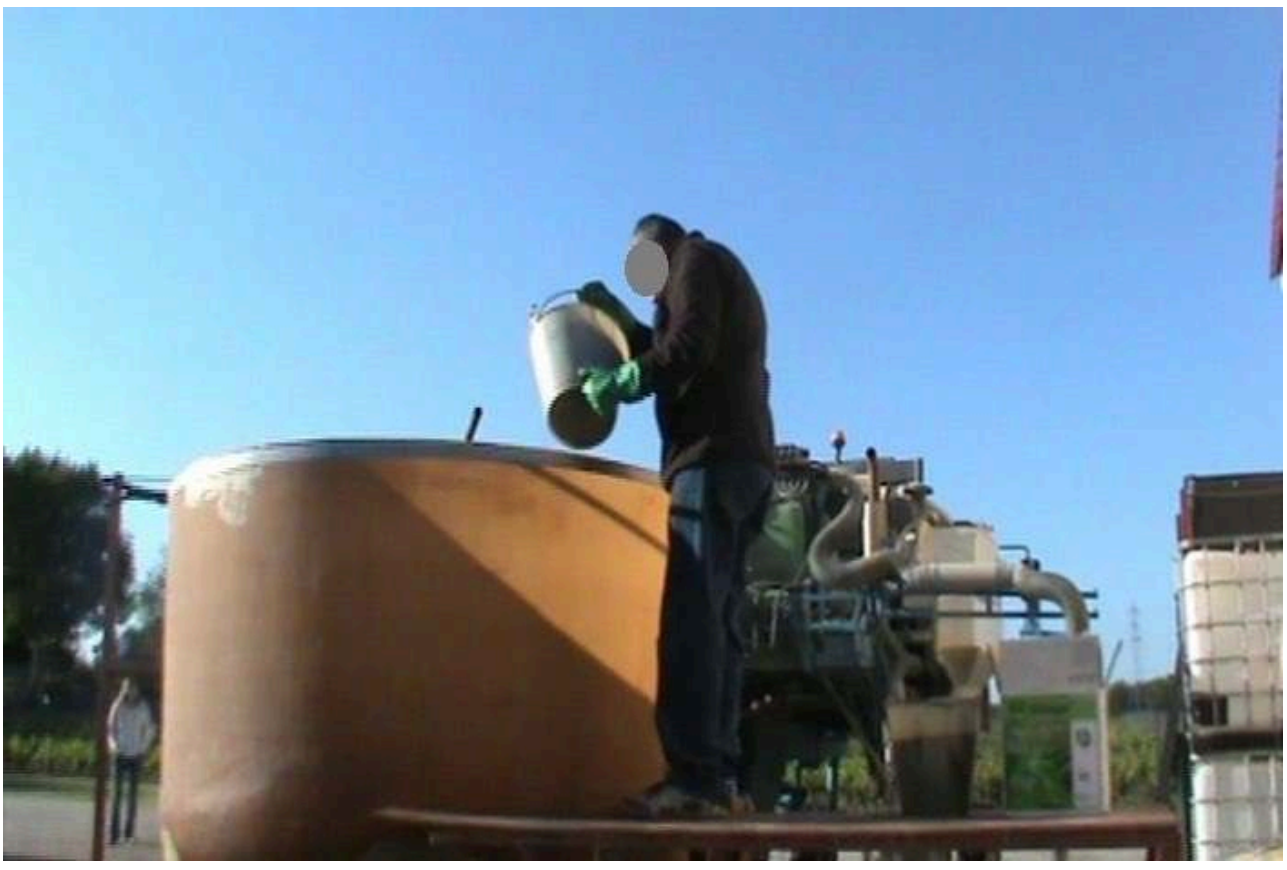

Figura 3: Limpieza del tractor luego de la aplicación

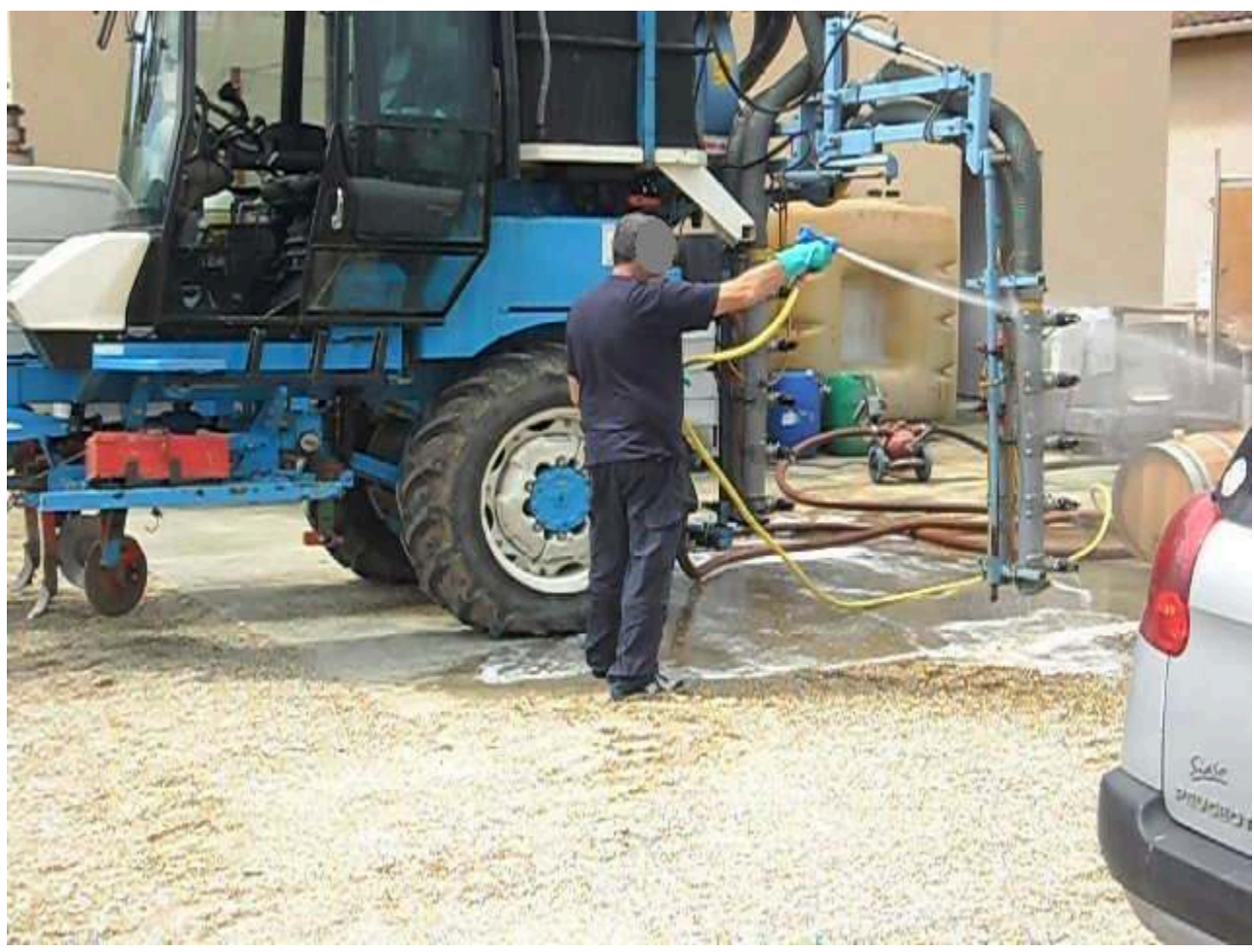

44 En otro momento, el V1 manipula bruscamente los pesticidas. En caso de una llamada telefónica a su celular, deja su actividad sacándose los guantes contaminados sin enjuagarlos previamente.

45 Cabe señalar que en su empresa, los cambios para la mejora son lentos, el director reconoce que si bien hay mejores materiales agrícolas, las inversiones se realizan en la 
medida de lo posible. Además, manifiesta su gran preocupación por la falta de personal debido a la dureza del trabajo y a los bajos salarios.

En cuanto a los viticultores del viñedo 2, su empleador les ha hablado de manera general, "hay que prestar atención, protegerse bien, utilizar la máscara, guantes, trajes de protección". Sin embargo, esto resulta insuficiente. Pues, cuando los viticultores se quitan los guantes, no los enjuagan y no cierran bien su traje pudiendo entrar partículas a su cuerpo. En caso de recibir una llamada telefónica, el V2 se quita sus guantes contaminados para sacar el celular de su camisa.

Figura 4: Contestando una llamada durante la preparación

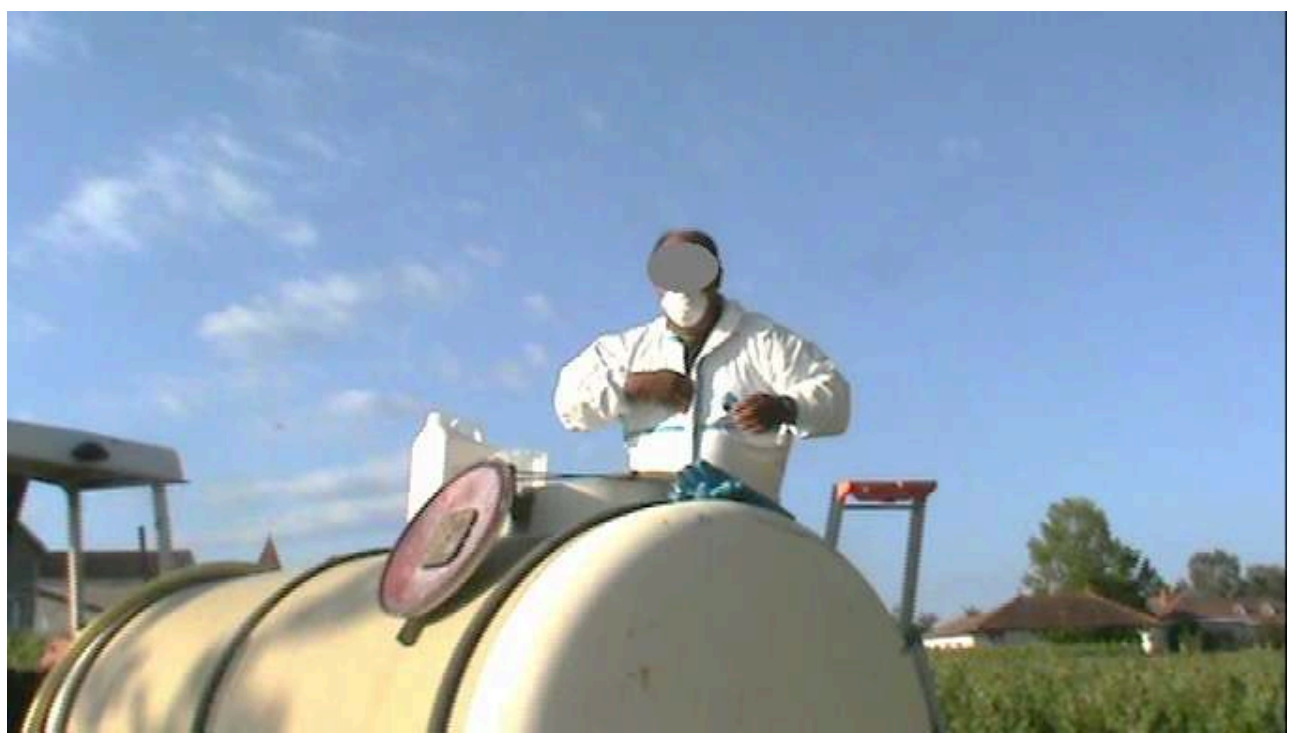

Por otro lado, el método de trabajo tradicional hace pocos años ha sido transformado gracias a la adquisición de nuevos tractores, por lo cual, los trabajadores recién perciben los cambios, pues dos de ellos vienen laborando más de 20 años. Antes había 6 personas y 4 de ellas se han jubilado, los dos que aún quedan deben hacer "lo que pueden ", asumiendo más responsabilidades, el jefe considera oneroso el contratar a otro conductor de tractor.

Por último, el V5 es el único trabajador que ha recibido formación tanto interna como externa por parte de los proveedores de la empresa; además de conocer qué equipos de protección debe utilizar para protegerse, conoce para qué sirven (ej. "guantes para evitar que las partículas atraviesen"). Trata de organizar sus materiales antes de desarrollar su faena y tiene claro la recomendación de no tocarlos directamente con sus manos.

En este caso, la empresa a la cual él pertenece, ha ido adquiriendo mejores materiales agrícolas, por lo cual el trabajador considera que las condiciones son más óptimas, lo cual le permite realizar otras tareas, señalando que no puede limitarse a ocupar solo su puesto, pudiendo compensar la falta de personal. 
Figura 5: Adición de pesticidas al pulverizador

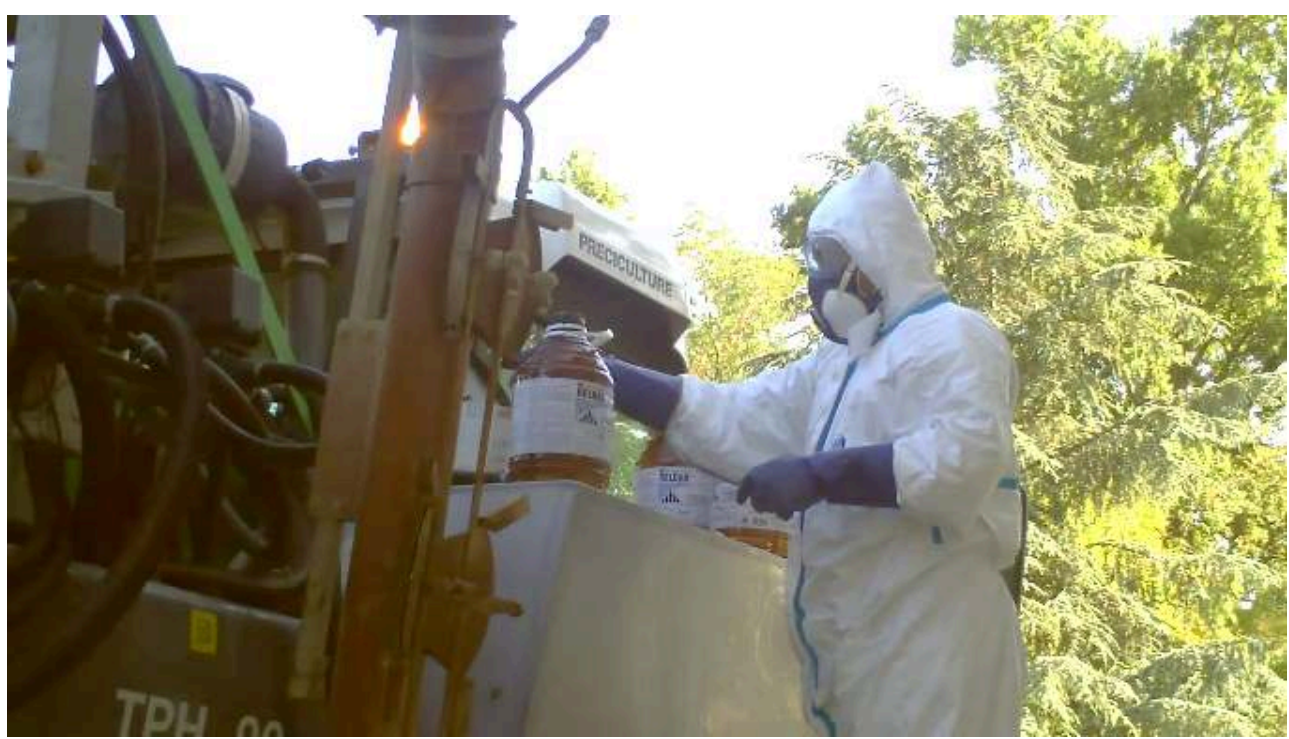

\subsection{Experiencia}

La experiencia adquirida a través de los años juega un rol importante, permitiendo desarrollar habilidades y competencias. Los V2, V3 y V5 tienen una antigüedad de 15 a 30 años realizando los tratamientos. El V4 recién se ha integrado al grupo del viñedo 2 y el V1 tiene 2 años dedicados a los tratamientos pero lleva más de 10 años laborando en el viñedo. La mayoría de ellos vienen de familias tradicionalmente vinícolas.

Observamos que los viticultores antiguos de poca o nula formación y con condiciones difíciles de trabajo, descuidan ciertas medidas de seguridad y las dificultades en cuanto a la utilización de sus materiales agrícolas se han convertido parte de su rutina laboral, manifestando:

V1: La viña no es un trabajo fácil, después es la habitud.

V2: Todo bien, yo estoy acostumbrado. Yo lo hago así desde hace 25 años.

V3: Es normal. Si yo no tengo eso, ¿qué hago?

En el caso de V4, dado que recién se ha integrado a la empresa, sus dificultades en la utilización de los materiales agrícolas son visibles a pesar de sus intenciones de protegerse. Por ejemplo, no puede retirar fácilmente las piezas pequeñas (ej. filtros), debiendo intentar varias veces y sacarse sus guantes entrando en contacto con el agua contaminada. 
Figura 6: Retiro de filtros

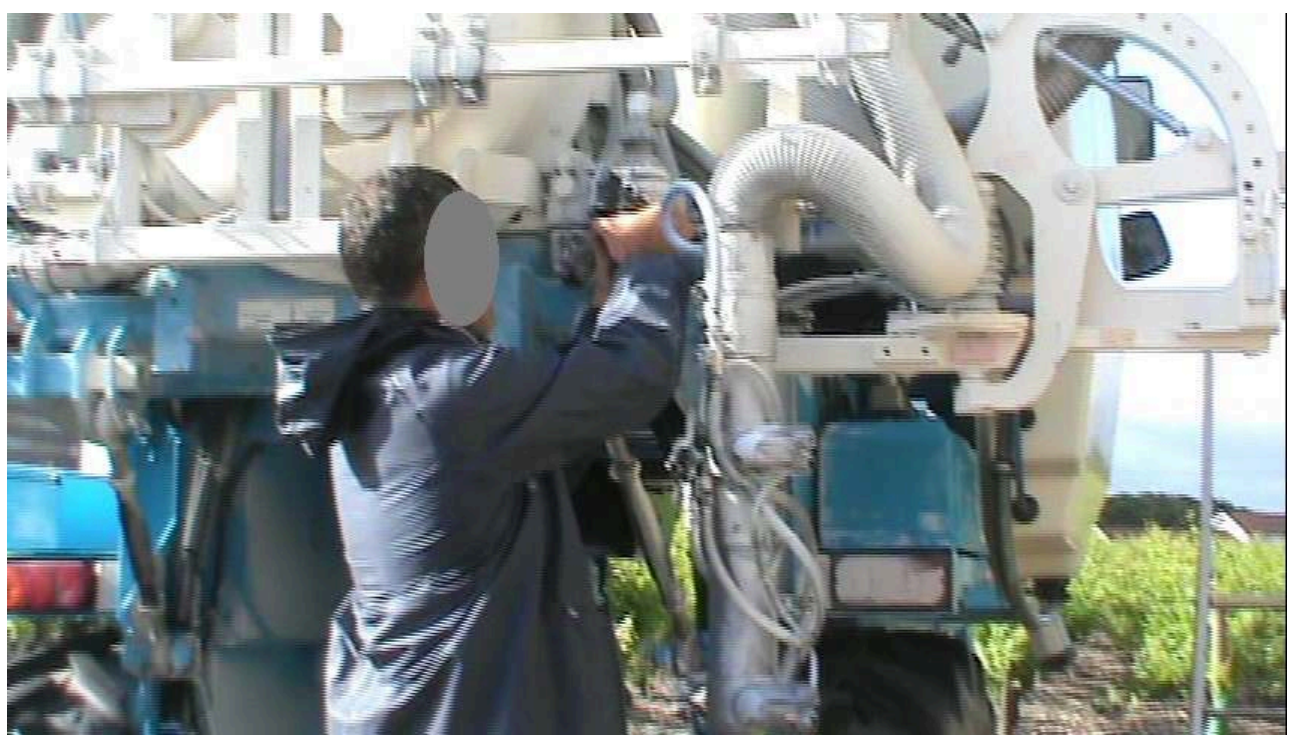

Contrariamente al V5 el cual tiene una formación más sólida, experiencia y mejores equipos de protección y materiales agrícolas en comparación a los otros viñedos, trata de evitar contaminarse en diferentes situaciones. Por ejemplo, para acceder a los comandos al interior de su cabina, en lugar de ingresar con sus equipos de protección contaminados, utiliza un accesorio adicional para alcanzarlos y regularlos desde afuera.

Figura 7: Utilización de un palo para acceder a los comandos

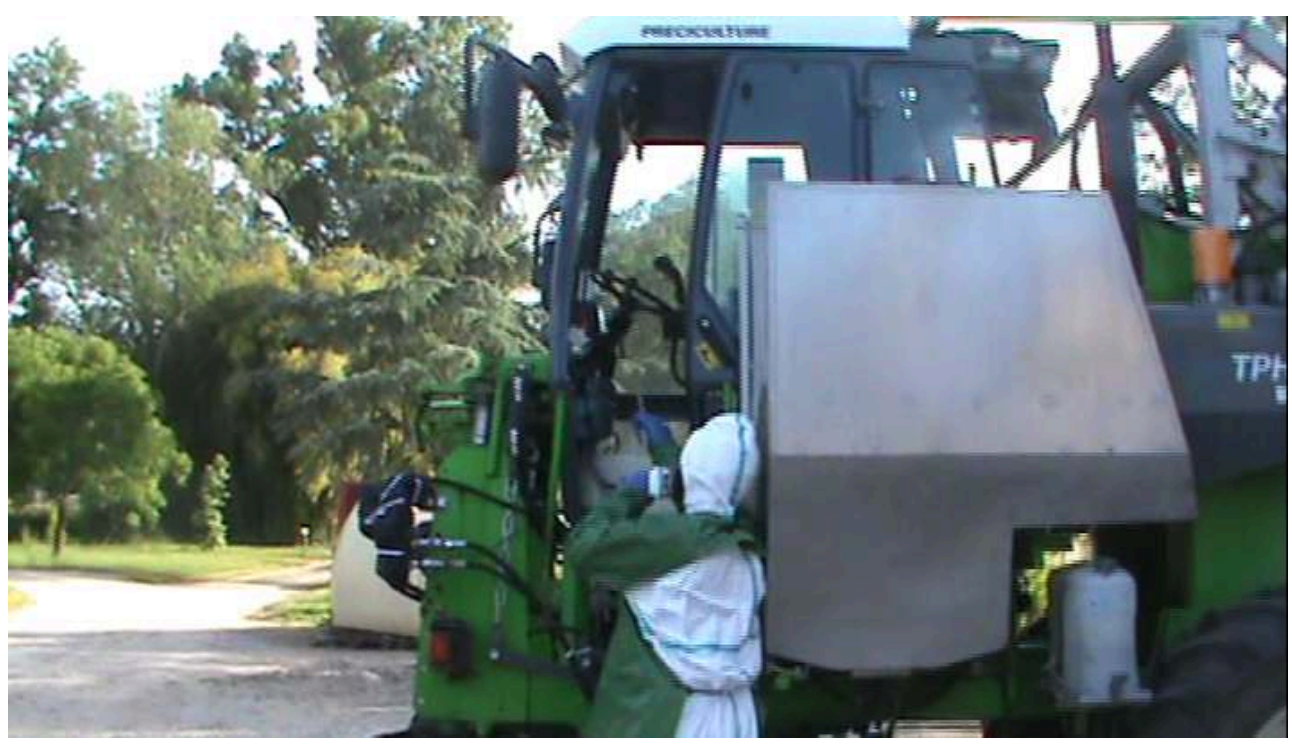

57 Por último, ningún viticultor lee las etiquetas de los envases de pesticidas en donde se señala ciertas medidas de seguridad, pues ellos justifican que utilizan continuamente los mismos productos y las indicaciones del fabricante son siempre las mismas.

\subsection{Creencias}

- Percepción de una amenaza 
cinco viticultores perciben los pesticidas como una amenaza para su salud debido a su toxicidad. Ellos son conscientes que no solo les afecta por su manipulación directa, sino también a aquellos que están alrededor de los cultivos, habiendo escuchado de casos de agricultores que han realizado los tratamientos por bastante tiempo y se han enfermado de cáncer.

- Minimización del riesgo

En este caso, el viticultor puede minimizar la importancia del riesgo descuidando ciertas medidas de seguridad por tener un concepto errado de los peligros a los que está expuesto, conduciendo a protegerse poco o incorrectamente.

detectó en varias observaciones que el V1 no utiliza mascara de protección y no cierra bien su traje durante el pesaje de los productos, a pesar de declarar que la exposición más fuerte es cuando vierte los pesticidas en forma de polvo ya que se forma una nube. Frente a esto, él justifica que ya todo lugar está contaminado "en el centro de la ciudad, no hay productos fito, pero están los carros que contaminan, así que no es peor".

El V3 utiliza una macara simple para polvos a pesar de manipular pesticidas en forma de líquidos que emanan vapores. Según él, “cuando no hay mucho polvo, está bien, pero cuando hay mucho polvo, sí. Es ahí (dónde se forma una nube de polvo), eso se mueve. Pero cuando hay mucho líquido, es tranquilo, es como el agua".

Siendo la presencia de polvo más visible a nuestros ojos, la emanación de vapores lo pasa desapercibido. El hecho de valorar a los pesticidas en su presentación líquida "como el agua", le conduce a no protegerse correctamente. Esto no sólo depende de él, pues su empleador debe asegurarse de proporcionar los correctos equipos y capacitar al personal en su uso y mantenimiento.

- Argumentos contradictorios

Algunos agricultores consideran que sus condiciones materiales de trabajo son las adecuadas, producto de que se han ido adaptando con el tiempo a lo que tienen, sin poner en evaluación la eficacia de éstas y sobre todo porque no han sufrido daños severos a su salud, sintiéndose inmunes.

Ciertos viticultores señalan sentirse protegidos con sus EPI, sin embargo, sus equipos no son los apropiados (ej. mascarilla simple en lugar de mascara con cartucho filtrante para vapores, zapatos en lugar de botas), o están en mal estado (ej. traje reutilizado con presencia de residuos) por no darles un buen mantenimiento o no son reemplazados oportunamente pues los trabajadores tienen tendencia a reutilizar sus mismos equipos de protección. Asimismo, algunos se contentan con tener sus equipos de protección sin cuestionar si éstos son los indicados en relación a los productos que manipulan o están expuestos. Ellos consideran que es necesario la utilización de los EPI, pero no toman atención a su correcta utilización.

- Argumentos de defensa

La búsqueda de ahorro de tiempo, la simplificación de los movimientos, la desvalorización de los EPI conducen a no tener una protección adecuada.

No colocarse los equipos de protección puede estar relacionado a la falta de costumbre o a la prisa, justificando esto con un probable olvido o a una pérdida de tiempo ya que tienen que avanzar y terminar su jornada laboral.

El V1 señala que "el traje no protege, de todos modos, al 100\%, nos ponemos para no ensuciarnos y además, a veces ni me lo pongo". Considera que no se siente protegido con los 
EPI y sólo utiliza el traje para no ensuciarse. Durante la limpieza de los materiales agrícolas sólo utiliza sus guantes de protección. Cuando retira los filtros del pulverizador, trata de sacarlos rápidamente y alejarse del agua que cae, pero estas acciones no limitan la exposición a salpicaduras de agua contaminada. En consecuencia, él prioriza su rutina de trabajo, dejando de lado las medidas de seguridad.

Además, el V1 es el único que realiza paradas de su tractor durante la aplicación de la mezcla a las plantas. En una oportunidad, salió de su cabina para constatar si la boquilla de un tubo estaba atorada, sin embargo, no utilizo guantes, señalando que se olvidó, entrando en contacto directo con la nube vaporizada con pesticida. Luego, detiene su tractor en la periferia del terreno en tres momentos, para lavar la luna de su cabina y enjuagar otras piezas. En estas situaciones, él considera que ponerse los EPI sólo para echar un chorro de agua es una pérdida de tiempo ya que aún le queda 4 a 5 horas para terminar sus tareas.

Figura 8: Parada al borde del campo

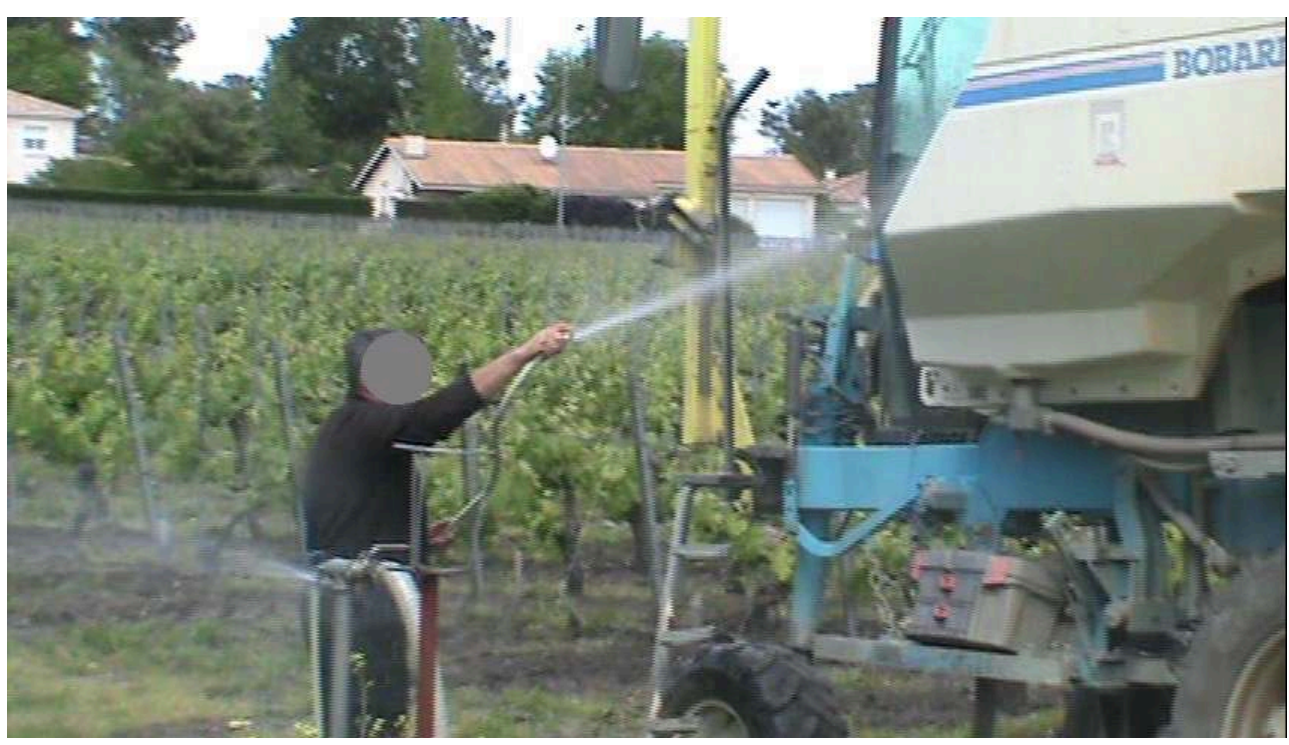

En el caso del V3 al llenar los tanques de cada lado del pulverizador, los cuales deben estar a un mismo nivel, señala que debe entrar a la cabina del tractor para hacerlo avanzar y retroceder, lo cual implica sacarse el traje de protección. Sin embargo, él atraviesa por la parte superior del tractor, justificando que lo hace "en lugar de bajar, sacarme los guantes (lavarlos), ponerme al volante". El trabajador prefiere ignorar estas medidas porque lo que hace "es más rápido", luego debe aplicar la mezcla a los cultivos por varias horas. 
Figuras 9-10: Atravesando por arriba del tractor y agarrando la manguera durante el llenado del tanque

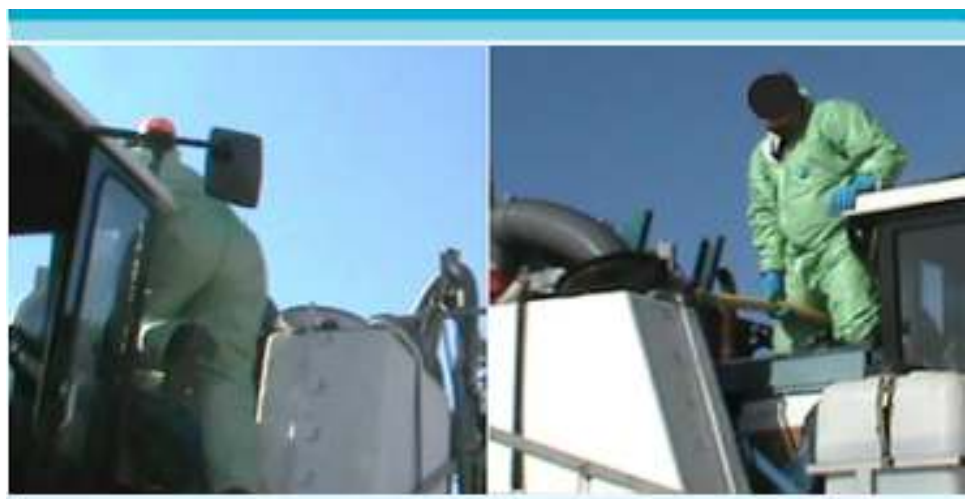

Figuras 9-10: Atravesando por arriba del tractor y agarrando la manguera durante el llenado del tanque.

Finalmente, una tarea importante que dura alrededor de 90 minutos, es la limpieza del tractor, el cual debe quedar "como nuevo", realizado en el viñedo 2 de manera exhaustiva para prevenir fallas de esta maquinaria. Esto obliga a adoptar posturas forzadas y aumenta el riesgo de contacto con las piezas contaminadas.

Durante esta tarea de limpieza, la utilización de los guantes es dejado de lado por dificultar la manipulación de piezas pequeñas. El V2 señala que no está seguro que la contaminación pueda darse por vía cutánea, según él, "estamos inmunizados, no arriesgamos nada (risas), yo no sé, tal vez (el pesticida puede penetrar)". Contrariamente, su colega V3 está convencido que los pesticidas pueden atravesar la piel y llegar a la sangre, pero en su rutina, no utiliza los guantes

Figura 11: Echando agua comprimida a diferentes partes del tractor pulverizador

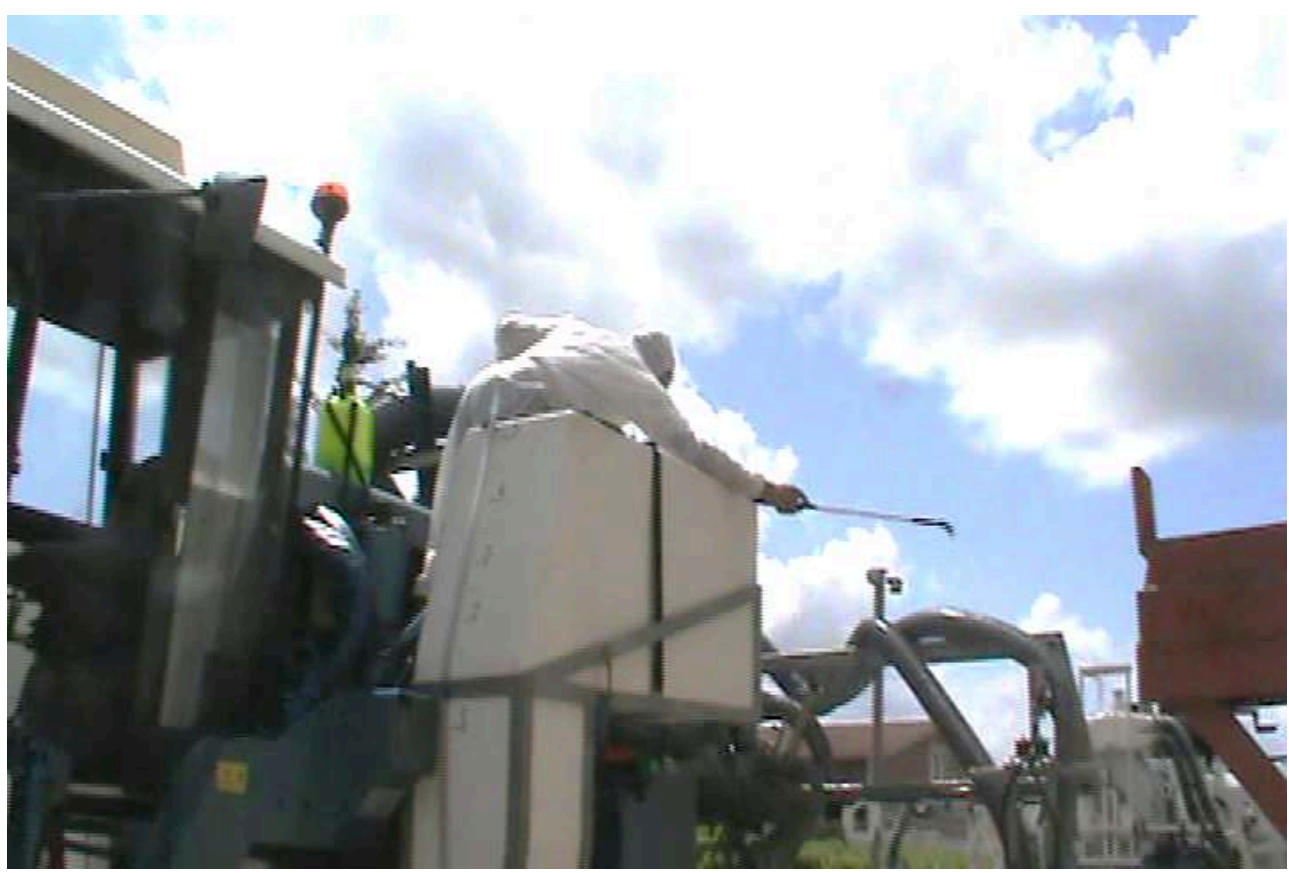

- Argumentos de preocupación 

de manipular cuidadosamente los productos y utilizar correctamente sus EPI.

Figura 12: Adicionado los pesticidas a un incorporador

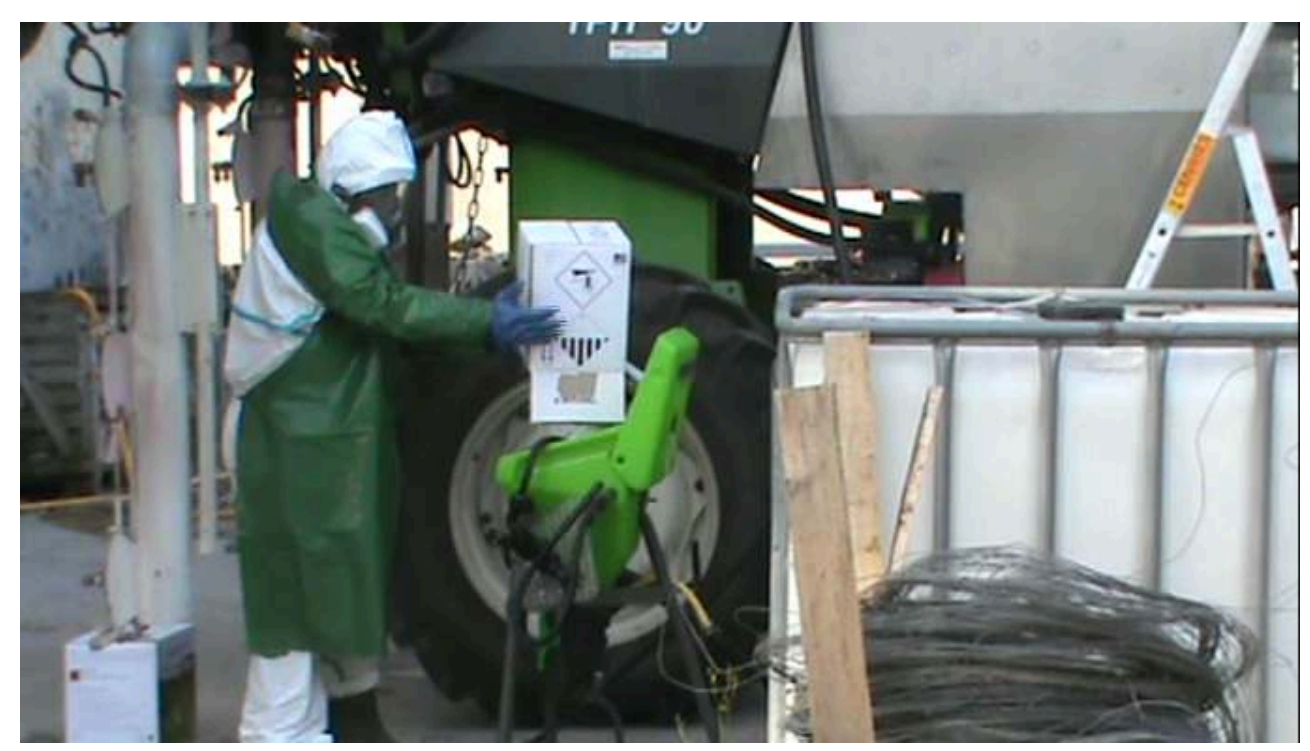

\section{Discusiones y Conclusiones}

El estudio permite explicar cómo el nivel de capacitación sobre la utilización de los EPI, la experiencia adquirida a través de los años y las diferentes creencias pueden influenciar de manera positiva o negativa, en la percepción del riesgo. Esto está influenciado también por el tipo de situaciones que vive el trabajador.

En caso de situaciones restrictivas sin posibilidad de modificar los medios de trabajos y los objetivos de producción, ciertas creencias pueden conducir a conductas que comprometen la salud y seguridad. Señalándose que una percepción adecuada del riesgo no es la única condición requerida para adoptar comportamientos seguros, pues la ausencia de condiciones seguras en el desempeño de la actividad laboral puede conducir a accidentes de trabajo.

En lo que concierne a las limitaciones del estudio, parece conveniente señalar: la falta de mediciones de la dosis de exposición, la falta de confrontación de los resultados a diferentes actores (ej. prevencionistas de la Mutualité Sociale Agricole, fabricantes de 
pesticidas, de materiales agrícolas, etc.), la limitada disponibilidad de los viticultores para las entrevistas, la dificultad para encontrar más viñedos.

Se considera que no sería responsabilidad del viticultor el cuestionar la eficacia de los EPI, siendo no suficiente su motivación y voluntad para protegerse. Los fabricantes de los diferentes dispositivos técnicos deben tomar en cuenta la diversidad de situaciones que conducen a la contaminación para ofrecer una mejor protección en términos de penetración de los pesticidas, evitando que sus diseños generen incomodidad y molestias para el desarrollo de las actividades. A título de ejemplo, los trajes de seguridad utilizados por los agricultores han sido diseñados para el sector de la industria, y no fueron probados con pesticidas, por lo tanto, la cuestión del diseño de los EPI puede considerarse un proceso complejo de transferencias de tecnología (Garrigou, Baldi 腪 Jackson, 2012).

Ahora bien, los ingenieros de prevención $u$ otros profesionales deben asegurarse de transmitir bien los mensajes de prevención, teniendo en cuenta la cultura laboral y creencias. Pues no basta con señalar los EPI, debe insistirse en la utilización adecuada y el mantenimiento periódico de éstos.

81 Resulta trascendental crear espacios de discusión e intercambio donde los trabajadores puedan expresar sus dificultades. La interacción entre los viticultores y prevencioncitas debe dar lugar a una "seguridad construida" (Amalberti, 2007). Es decir, una seguridad dinámica que no se base únicamente en hacer descender reglas formales sino también tomar en cuenta (ascender) los comportamientos de iniciativa de parte de los operadores para enfrentar las variabilidades, las situaciones particulares y los disfuncionamientos.

Finalmente, futuras investigaciones deberían permitir una mejor explicación de los comportamientos a través de la articulación tanto de factores internos como externos, la medición de la dosis de exposición y la movilización de diferentes actores para una mejor reflexión de los factores. Deseamos también que nuestro estudio pueda ser realizado en países de América Latina donde la vigilancia en el empleo de pesticidas es limitada.

\section{BIBLIOGRAFÍA}

Amalberti, R. (2007). Ultrasécurité. Une épée de Damoclès pour les hautes technologies. Les dossiers de la recherche, 26, 74-81.

Aubertot, J.N., Barbier, J.M., Carpentier, A., Gril, J.J., Guichard, L., Lucas, Savary, S., Savini, I., \& Voltz, M. (2005). Pesticides, agriculture et environnement. Réduire l'utilisation des pesticides et limiter leurs impacts environnementaux. Rapport d'Expertise scientifique collective. Francia : INRA \& Cemagref.

Baert, A., Bard, D., Especel, J., Eugène J. P., Garnier, B., Hamonet, B., Joseph, O., Kurz, H., Laurent, M., Marchand, D., \& Péron, L. (2003). Perceptions des risques sanitaires encourus par les utilisateurs de pesticides. Enquête. Bretagne : URCAM \& DRASS. 
Baldi, I., Filleul, L., Mohammed-Brahim, B., Fabrigoule, C., Dartigues, J. F., Schwall, S., Drevet, J. P., Salamon, R., [26 Brochard, P. (2001) Neuropsychologic effects of long-term exposure to pesticides: results from the French Phytoner study. Environmental Health Perspectives, 109, 839-844.

Baldi, I., Lebailly, P., Jean, S., Rougetet, L., Dulaurent, S., 廢 Marquet, P. (2006). Pesticide contamination of workers in vineyards in France. Journal of Exposure Analysis and Environmental Epidemiology, 16, 115-124.

Baldi, I., Gruber, A., Rondeau, V., Lebailly, P., Brochard, P., [20 Fabrigoule, C. (2011).

Neurobehavioral effects of long-term exposure to pesticides: results from the 4-year follow-up of the PHYTONER Study. Occup Environ Med, 68, 108-115.

Cahour, B. (2006). L'expérience vécue des utilisateurs : pourquoi l'étudier et comment? Actes du colloque CITE. Nantes, France.

Chevreau, F. (2009). Maitrise des risques industriels et culture de sécurité : le cas de la chimie pharmaceutique. Thèse de sciences et génie des activités à risques. École des Mines de Paris.

Duclos, D. (1987). La construction sociale du risque : le cas des ouvriers de la chimie face aux dangers industriels. Revue française de sociologie, 28, 17-42.

Fenske, R.A., ${ }_{20}^{06}$ Day, E.W. (2005). Assessment of exposure for pesticide handlers in agricultural, residential and institutional environments. In C.A. Franklin 澄 J.P. Worgan (Eds.), Occupational and Residential Exposure Assessment for Pesticides (pp. 13-43). Chichester, UK : Wiley [56 Sons.

Garrigou, A., Baldi, I., [20 ${ }_{20}^{6}$ Dubuc, P. (2008). Apports de l'ergotoxicologie à l'évaluation de l'efficacité réelle des EPI devant protéger du risque phytosanitaire : de l'analyse de la contamination au processus collectif d'alerte. Pistes, 10, 17 pages.

Garrigou, A., Baldi, I., 澄 Jackson, M. (2012). The use of pesticides in french viticulture : a badly controlled technologie transfert! Work, 41, 19-25. Brazil : IEA.

Gatignol, C., \& Étienne, J-C (2010). Rapport sur Pesticides et Santé. Office parlementaire d'évaluation des choix scientifiques et technologiques.

Institut National de la Statistique et des Études Économiques (INSEE), France. Retirado março, 21, 2016 de http://www.insee.fr/fr/themes/document.asp?ref_id=T13F172\#tableaux

Kouabenan D. R. (2006a). Introduction : Psychologie du risque ou pourquoi étudier la perception et l'évaluation du risque ? In Kouabenan D. R., Cadet Bernard D.H., [20 Muños Sastre M.T. (Eds.), Psychologie du risque (pp. 7-15). Bruxelles : Éditions De Boeck Université.

Kouabenan D. R. (2006b). Des facteurs structurants aux biais ou illusions dans la perception des risques. In Kouabenan D. R., Cadet Bernard D.H., 澄 Muños Sastre M.T. (Eds.), Psychologie du risque (pp. 125-145). Bruxelles : Éditions De Boeck Université.

Kouabenan, D.R. (2008). Rôle des croyances dans le management de la sécurité. Congrès de l'Association (Francophone) de Gestion des Ressources Humaines (AGRH). Dakar, Senegal.

Multigner M. (2005). Effets retardés des pesticides sur la santé humaine. Environnement, Risques et Santé, 4, 187-194.

\section{NOTAS}

1. Los resultados de este artículo forman parte de nuestra investigación "L'apport de l'analyse de la prise de risque à la compréhension des difficultés rencontrés par les viticulteurs pour se protéger des pesticides", realizada durante el stage de recherche en el departamento de Hygiène, 
Sécurité et Environnement (HSE) de la Universidad de Bordeaux 1, en el ámbito de la maestría de Ergonomía de la universidad Paris Sud XI.

2. Tipos de viticultura: biológica (sin empleo de productos químicos), convencional (empleo de productos químicos), razonada (empleo de manera razonada de productos químicos).

\section{RESÚMENES}

El uso de los pesticidas puede ocasionar daños considerables a la salud humana. Una serie de esfuerzos se han llevado a cabo para reducir la exposición profesional, pero no han sido suficientes. En lo que concierne al diseño de los equipos de protección individual, éstos presentan ciertas limitaciones impidiendo garantizar una protección segura. La no utilización o utilización incorrecta de estos equipos puede conllevar a consecuencias negativas. El objetivo de este artículo es explicar la influencia de la percepción del riesgo en el comportamiento de los viticultores para protegerse contra los pesticidas. La metodología se basa en el análisis de la actividad buscando comprender sus estrategias laborales. Los resultados de nuestro estudio cualitativo realizado a una muestra de cinco viticultores, muestran que el nivel de capacitación, la experiencia y las creencias pueden influir, de forma positiva o negativa, en la percepción del riesgo.

O uso de pesticidas podem causar danos consideráveis à saúde humana. Uma série de esforços têm sido realizados para reduzir a exposição ocupacional, mas não têm sido suficientes. No que diz respeito à conceção de equipamentos de proteção individual, estes apresentam certas limitações impedindo a garantia de uma protecção segura. O não uso ou uso indevido destes equipamentos pode levar a consequências negativas. O objetivo deste artigo é explicar a influência da perceção de risco sobre o comportamento dos viticultores para se proteger contra os pesticidas. A metodologia baseia-se na análise da atividade procurando compreender as suas estratégias de trabalho. Os resultados do nosso estudo qualitativo realizado com uma amostra de cinco viticultores, mostram que o nível de formação, a experiência e as crenças podem influenciar, de forma positiva ou negativa, a percepção de risco.

L'usage des pesticides peut occasionner des dommages pour la santé. Une série d'efforts ont été réalisés pour réduire l'exposition professionnelle, mais toujours insuffisante. En ce qui concerne la conception des équipements de protection individuelle, ceux-ci présentent certaines limitations en empêchant d'assurer une protection sûre. La non-utilisation ou l'utilisation incorrecte de ces équipements peuvent conduire à des conséquences négatives. L'objectif de l'article est d'expliquer l'influence de la perception du risque sur le comportement des viticulteurs pour se protéger des pesticides. La méthodologie se base sur l'analyse de l'activité, en cherchant de comprendre leurs stratégies de travail. Les résultats de notre étude qualitative portant sur cinq viticulteurs, montrent que le niveau de formation, l'expérience et les croyances peuvent influencer, de façon positive ou négative, sur la perception du risque.

The use of pesticides can cause considerable damage to human health. A number of efforts have been made to reduce occupational exposure, but it has not been sufficient. In relation to personal protective equipment, it has certain limitations, hence preventing a reliable protection. Non-use or misuse of this equipment can lead to negative consequences. The aim of this article is to explain the influence of risk perception on the behaviour of winegrowers to protect themselves 
against pesticides. The methodology is based on the analysis of the activity seeking to understand its work strategies. The results of our qualitative study with a sample of five winegrowers show that the training level, the experience and the beliefs can have an influence, positively or negatively, on risk perception.

\section{ÍNDICE}

Keywords: behaviour, risk perception, beliefs, prevention

Palavras-chave: comportamento, percepção de risco, crenças, prevenção

Mots-clés: comportement, perception du risque, croyance

Palabras claves: comportamiento, percepción del riesgo, creencias, prevención

\section{AUTORES}

\section{CAROLINA ULLILEN-MARCILLA}

Facultad de Ingeniería Ambiental, Escuela Profesional de Ingeniería de Higiene y Seguridad Industrial, Universidad Nacional de Ingeniería, Av. Túpac Amaru 210, Rímac. Lima 21, Perú. cullilenm@uni.edu.pe

\section{ALAIN GARRIGOU}

Département HSE, IUT de Bordeaux, Equipe EPICENE, Inserm U1219, Université de Bordeaux, 15, rue Naudet CS 10207 - 33175 Gradignan Cedex, France alain.garrigou@u-bordeaux.fr 